\title{
Growth and leadership amid a pandemic
}

Yia Swam Tan, MBBS, FRCS

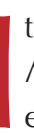
thank A/Prof Poh Kian Keong, Editor-in-chief of the Singapore Medical Journal (SM), for the invitation to write an editorial for the $S M$ J as President of the Singapore Medical Association (SMA) Council. The SMJ has come a long way from its first issue in March 1960, with Dr Gwee Ah Leng as the first Editor. The focus then was on public health, common infectious diseases and vaccinations. The journal now has a good range of papers encompassing different specialties. In recent months, the team has worked hard to curate articles on coronavirus disease 2019 (COVID-19) that serve to document and guide local practice.

In my 12 years on the SMA Council, the SMJ has evolved and grown. In the past few years, we have seen its impact factor rise from 0.67 in 2016 to the current 1.359, under the leadership and direction of A/Prof Poh. The specialty editors have also put in a lot of time and effort to ensure that publications are of good quality and a reliable source of up-to-date medical information.

The Council is truly appreciative, and as the newly elected President of SMA, I would like to thank the SM/ team: the Editorin-chief, speciality editors, reviewers and the publication team. I must also thank you, the reader, for referring to the $S M$ J as a reliable source for medical updates, especially for locoregional data. I am confident that the SM/ will continue to grow and, in time, become the regional leading scientific journal.

As I have alluded to in my President's Forum in SMA News, one of our biggest enemies against COVID-19, especially in this age of social media, is 'fake news'. Rather than reading popular writings on social media websites, we should be going straight to the source articles. When reading medical journals, critical thinking and analysis become even more important in helping us discern the 'truth'. In addition, even when we quote research papers, we should be acutely aware of the different levels of evidence and the inherent strengths, weaknesses, limitations or biases of any paper.

After we complete our clinical training, many of us put our patients and clinical work first. As we become mature clinicians, we may take on additional roles as academics, administrators or educators. While not everyone will become a top researcher, each and every one of us should have the mental capacity and training to read a science paper critically. This is not my core strength, but it is necessary to keep up to date so as to better guide my patients.

This April, I was elected to the post of President of the SMA Council. These past three months have been personally challenging. The challenges started from January this year, even before COVID-19 arrived in Singapore, as the Council was involved in COVID-19 support for all doctors. Subsequently, I had an overview of the many problems besetting our profession - so many problems and not enough solutions. What was especially disheartening were the few colleagues who were openly antagonistic towards SMA, making personal demands on me to solve these problems. I can only hope that the discerning readers of the $S M$ J can appreciate the magnitude of systemic problems and understand that solving such problems takes a combined effort from various parties as like-minded individuals, all with common goals.

As I continue to serve my term as President, I will do my best to advocate for doctors. I ask for your support in SMA as well. If you are not already a member, please consider joining us at https://www.sma.org.sg/membership.

SMA is for doctors, by doctors. If we do not help ourselves, no one else will. The stronger the SMA membership numbers, the greater is the representative power of the President for all of us. 